\title{
Reconstituição de uma poligonal topográfica pelo sistema de posicionamento global. Planimetria
}

\author{
Reconstitution of a topographic poligonal by the global \\ positioning system. Planimetry
}

Cláudia Weber Corseuil ${ }^{1}$ Adroaldo Dias Robaina ${ }^{2}$

\section{RESUMO}

Este estudo tem por objetivo verificar a influência do tempo de coleta de dados com receptores GPS na reconstituição de uma poligonal topográfica. O levantamento da poligonal é realizado através do método de posicionamento relativo estático. São utilizados dois receptores GPS de uma freqüencia, em diferentes tempos de ocupação dos pontos (30, 15,10 e 5 minutos) com uma taxa de gravação de $2 \mathrm{~s}$. Os resultados do levantamento com receptores GPS são comparados com as distâncias, azimutes, projeções horizontais, ângulos horizontais e as áreas obtidas de um polígono, cujos elementos topográficos foram determinados por caminhamento perimétrico utilizando uma Estação Total. Os ângulos do polígono levantado por Estação Total, foram calculados através da média de 24 leituras e as distâncias através da média de 12 leituras. Os resultados mostram que a reconstituição de uma poligonal topográfica depende da qualidade dos dados coletados pelos receptores GPS, sendo influenciada pelo tempo de ocupação dos pontos. O tempo de ocupação de 15 minutos demonstra ser o mais adequado para a obtenção de uma diferença centimétrica nos elementos da poligonal que são analisados.

Palavras-chave: levantamento topográfico, sistema GPS, método relativo estático.

\section{ABSTRACT}

The objective of this study is to verify the time influence of the GPS receivers for data acquisition in the reconstitution of a topographic polygonal. The determination of the polygonal is determined by the relative static positioning method using two of one frequency GPS receivers at different occupation periods of points (30,15, 10 and 5 minutes), with a two second recording rate. Results of the determination using GPS receivers are compared with the distances, azimuths, horizontal projections, horizontal angles, and the obtained areas of a polygon, on which the topographic elements of this polygon are determined by the perimetrical path using a Total Station. The angles of the polygon obtained by Total Station were calculated by the average of 24 readings and the distances by the average of 12 readings. The results show that the reconstitution of a topographic polygonal depends on the quality of the data collected with the GPS receivers, which are influenced by the time of the occupation points. The 15 minute, occupation time seems to be more appropriated, presenting a small difference (a few centimeters) with respect to the polygonal elements that were analyzed.

Key words: topographic survey, system GPS, relative static method.

\section{INTRODUÇÃO}

As ciências relacionadas aos estudos da Terra sofreram avanços significativos, tanto nos métodos de levantamentos como nos instrumentos utilizados para medir as feições do terreno. Um dos adventos mais importantes da tecnologia utilizada nos levantamentos sobre a superfície da Terra foi o surgimento do Sistema de Posicionamento Global, conhecido mundi-

\footnotetext{
${ }^{1}$ Engenheiro Florestal, Doutoranda em Agronomia, Departamento de Engenharia Rural, FCA/UNESP Fazenda Experimental Lajeado, 18603-970, Botucatu, SP. Email:. cwcorseuil@fca.unesp.br. Autor para correspondência.

${ }^{2}$ Engenheiro Agrônomo, Professor Titular, Departamento de Engenharia Rural, Centro de Ciências Rurais, Universidade Federal de Santa Maria. Email: arobaina@ccr.ufsm.br.
} 
almente pela sigla GPS. Segundo LAZAROTTO (2000), o GPS é um sistema de navegação eletrônica baseado numa rede de satélites artificiais que permitem a obtenção instantânea do posicionamento tridimensional (latitude, longitude e altitude), velocidade e tempo. Estas informações podem ser obtidas em qualquer ponto da superfície terrestre, a qualquer momento, sob quaisquer condições atmosféricas, ininterruptamente.

A utilização do GPS nos levantamentos geodésicos para fins topográficos oferece uma série de vantagens no que diz respeito à eficiência na coleta e automação dos dados, à dispensa de intervisibilidade entre vértices e a possibilidade de transporte simultâneo de coordenadas tridimensionais (X, Y e Z), sob qualquer condição atmosférica e em qualquer hora do dia. Com o crescente interesse pela utilização do sistema GPS para medições geodésicas de curta distância, foram desenvolvidos vários métodos de posicionamento, dentre os quais se destaca o método relativo estático. Este método é aquele em que dois ou mais receptores GPS permanecem fixos observando os mesmos satélites durante todo o tempo de ocupação dos pontos, sendo que um dos receptores é instalado sobre um ponto de coordenadas conhecidas e o(s) outro(s) no(s) ponto(s) a determinar (MAIA, 1999). Com o rastreamento simultâneo de satélites GPS, por um intervalo de tempo recomendado (aproximadamente uma hora), são calculadas as coordenadas tridimensionais (latitude, longitude e altitude) do ponto desconhecido. A principal vantagem do método é a sua maior precisão, quando comparado com outros métodos de posicionamento e a sua principal desvantagem, para uso em levantamentos topográficos é o seu elevado tempo de permanência recomendado para a coleta de dados.

Para os levantamentos topográficos, surge a questão sobre qual é o tempo necessário de permanência ou ocupação no ponto com receptores GPS de uma freqüência, para obter a precisão nos levantamentos desse tipo, que possa substituir, adequadamente, as técnicas convencionais utilizadas em topografia.

A justificativa para esta pesquisa pauta-se na necessidade de obter subsídios teóricos e metodológicos para a utilização da tecnologia GPS na determinação de medidas topográficas distâncias, ângulos e áreas, com precisão adequada aos levantamentos topográficos em um curto intervalo de tempo de ocupação dos pontos de uma poligonal.

O objetivo desse trabalho foi verificar a influência dos diferentes tempos de coleta de dados (tempo de ocupação e permanência) nos pontos, com uma taxa de gravação de $2 \mathrm{~s}$, para a reconstituição de uma poligonal topográfica, utilizando receptores GPS de uma freqüência.

\section{MATERIAL E MÉTODOS}

O trabalho foi realizado no Campus da Universidade Federal de Santa Maria (RS) numa área localizada entre as coordenadas geográficas $29^{\circ} 42^{\prime} 50^{\prime \prime} \mathrm{e}$ $29^{\circ} 43^{\prime}$ '09" de latitude S7ul, $53^{\circ} 42$ ' $25^{\prime}$ " e $53^{\circ} 42$ ' $50^{\prime \prime}$ ' de longitude Oeste e altitude ortométrica média de $100 \mathrm{~m}$, aproximadamente. A área em estudo consiste em um polígono fechado com 5 vértices, selecionados de uma poligonal maior, implantada em 1999 pelo Professor Gomercindo G. M. Marques do departamento de Engenharia Rural da UFSM. Em relação aos pontos topográficos dos vértices, cujas coordenadas foram calculadas analiticamente a partir das medidas dos ângulos horizontais internos (média de 12 leituras) e das distâncias entre estações (média de 24 leituras), obtidas por caminhamento perimétrico, utilizando um sistema de centragem forçada e uma Estação Total com precisão angular de 1" e linear de $1 \mathrm{~mm}$, o erro angular foi da ordem de 32 " e o erro linear de fechamento foi de 14,8 ppm.

No levantamento dos dados, foram utilizados dois receptores GPS de uma freqüência e de modelos diferentes para a estação base e para os pontos da poligonal. No ponto de coordenadas conhecidas (estação base ou Ponto B), foi utilizado um receptor GPS da marca TOPCON, modelo GP-R1, com 12 canais paralelos e independentes para recepção dos sinais dos satélites, cuja precisão alcançada no pósprocessamento dos dados é de $5 \mathrm{~mm} \pm 2 \mathrm{ppm}$ (TOPCON AMERICA CORPORATION, 1993). Nos pontos P1, P2, P3, P4 e P5, utilizou-se um receptor da marca SOKKIA, modelo GSS1A, com 8 canais paralelos e independentes. No processamento dos dados, a precisão fornecida é de $5 \mathrm{~mm} \pm 1 \mathrm{ppm}$ (SOKKIA, 1999a). A antena da estação base permaneceu fixa no ponto de coordenadas conhecidas (Ponto B) e a outra foi instalada em cada ponto da poligonal (P1, P2, P3, P4 e P5).

$\mathrm{O}$ processamento dos dados foi feito no programa computacional SPECTRUM SURVEY, versão 1.20. Os dados coletados pelo receptor base foram convertidos para o formato RINEX (Receiver Independent Exchange), que é um formato universal utilizado para entrada de dados na maioria dos programas computacionais de processamento de dados obtidos com receptores GPS.

No presente estudo, foi utilizado o posicionamento relativo estático, no qual as coordenadas de um ponto desconhecido são determinadas em relação a um ponto de coordenadas conhecidas (base). A antena do receptor base foi instalada no Ponto $\mathrm{B}$, localizado no prédio 42 do Centro de Ciências Rurais (CCR) da UFSM, com coordenadas geográficas 
$29^{\circ} 43^{\prime} 04,9200^{\prime \prime} \mathrm{S}$ e $53^{\circ} 43^{\prime} 00,4300^{\prime \prime} \mathrm{W}$ e altitude geométrica de $129,0373 \mathrm{~m}$. Esse ponto fica a uma distância inferior a $1 \mathrm{~km}$ dos pontos da poligonal (P1, P2, P3, P4 e P5) e livre de obstáculos, que possam interferir na recepção dos sinais dos satélites. O receptor do Ponto $\mathrm{B}$ foi configurado para coletar os dados com uma taxa de gravação de $2 \mathrm{~s}$ e ângulo de corte de $10^{\circ}$, permanecendo ligado durante toda a sessão de observação. $\mathrm{O}$ receptor utilizado nos pontos da poligonal recebeu a mesma configuração do receptor instalado no Ponto $\mathrm{B}$, no que se refere à taxa de gravação de $2 \mathrm{~s}$, diferindo quanto ao ângulo de corte utilizado, que foi de $15^{\circ}$. A antena desse receptor foi instalada sobre os pontos topográficos da poligonal a uma altura de $2,500 \mathrm{~m}$, controlada por um dispositivo de regulagem de altura e devidamente fixada a um suporte bipé dotado de um nível de bolha, para permitir a verticalização da antena sobre o ponto topográfico escolhido. Foram realizadas sessões de observações com um tempo de ocupação de 30 minutos em cada ponto e uma taxa de gravação dos dados de $2 \mathrm{~s}$. Esse tempo foi escolhido de acordo com as orientações de HOFMANN-WELLENHOF et al. (1997), que fornece o tempo de duração das sessões em função da distância entre o receptor colocado na base e o receptor posicionado no ponto a determinar. Os arquivos de 30 minutos de observação, que correspondem a 900 épocas foram, fracionados em arquivos de 15,10 e 5 minutos correspondendo a 450, 300 e 150 épocas, respectivamente. Os dados coletados com os receptores, em cada tempo de ocupação (30, 15,10 e 5 minutos) foram processados no programa SPECTRUM SURVEY 1.20, utilizando-se a equação da dupla-diferença de fase para determinação das coordenadas geocêntricas dos pontos da poligonal (SOKKIA, 1999b). As informações solicitadas para o processamento dos dados foram: as coordenadas geográficas da estação base (latitude $/ \varphi$, longitude $/ \lambda$ e altitude geométrica/h ), altura da antena da estação base $(0,0 \mathrm{~m})$, altura da antena nos pontos P1, P2, P3, P4 e P5 (2,5 m), opção de correção da ionosfera (Sim) e forma de seleção do satélite de referência (satélite mais alto). O programa de processamento dos dados fornece as coordenadas geocêntricas (coordenadas determinadas em relação ao centro de massa da Terra) tridimensionais (X, Y e Z), referidas ao WGS 84 (World Geodetic System 1984), um sistema de referência global. As coordenadas no sistema global dos pontos da poligonal, para cada tempo de ocupação de 30, 15, 10 e 5 minutos, foram transformadas para um sistema de coordenadas com referência local, para serem comparadas com as coordenadas da poligonal teste, levantada com Estação Total. As coordenadas dos pontos referidas ao sistema WGS 84 foram transformadas para o sistema topográfico local, através de um procedimento descrito em HOFMANN-WELLENHOF et al. (1997). Para atender esse objetivo, foi utilizada uma rotina computacional desenvolvida no Laboratório de Geomática do Dep. de Engenharia Rural da UFSM. Conhecidas as coordenadas geocêntricas tridimensionais ou elipsoidais $(\mathrm{X}, \mathrm{Y}$ e Z $)$ e as coordenadas geodésicas $(\varphi, \lambda$ e h $)$ dô ponto de referência (Ponto B) e as coordenadas geocêntricas tridimensionais (X, Y e Z) dos pontos $\mathrm{P} 1, \mathrm{P} 2, \mathrm{P} 3, \mathrm{P} 4 \mathrm{e}$ $\mathrm{P} 5$, pode-se determinar a diferença de coordenadas geocêntricas $(\Delta \mathrm{X}, \Delta \mathrm{Y}$ e $\Delta \mathrm{Z})$ entre cada ponto e o Ponto $B$. A rotina calcula a distância inclinada (DI), o ângulo zenital (Ze), o azimute (Az) dos alinhamentos, a distância horizontal (DH), a diferença de altitude geométrica $(\Delta \mathrm{h})$ de cada ponto considerado com a base (Ponto B) e as coordenadas planas (Cx, Cy e $\mathrm{Cz}$ ) dos pontos no sistema local, referidas a mesma origem da poligonal em estudo (translação da origem).

Para cada tempo de ocupação nos pontos (30, 15, 10 e 5 minutos), foi obtida uma planilha de dados, reconstituídos a partir dos cálculos efetuados com base nos resultados obtidos através do levantamento com os receptores GPS. Os dados utilizados para comparação foram: as distâncias, as coordenadas (Cx e Cy) de cada ponto da poligonal e as áreas.

O levantamento do polígono com o sistema GPS foi realizado pelo método de irradiação e o polígono de comparação teve seus elementos calculados a partir do caminhamento perimétrico. Desse modo, as distâncias, os azimutes, os ângulos internos, as projeções em X e as projeções em Y foram recalculados, a fim de permitirem a comparação dos elementos do polígono teste (PGT) e os obtidos com os receptores GPS nos quatro tempos de ocupação dos pontos.

\section{RESULTADOS E DISCUSSÃO}

\section{Distâncias dos alinhamentos}

A tabela 1 apresenta as distâncias dos alinhamentos do polígono teste (PGT) e as distâncias dos alinhamentos determinadas com os receptores GPS nos quatro tempos de ocupação, mostrando também as diferenças $(\Delta)$ obtidas entre as duas técnicas. A partir da tabela 1, observa-se que, nos quatro tempos de ocupação dos pontos (30, 15, 10 e 5 minutos), todas as diferenças entre as distâncias do PGT e as obtidas com GPS foram centimétricas. Para os tempos de $30 \mathrm{e}$ 15 minutos, estas diferenças foram menores do que as determinadas com 10 e 5 minutos.

$\mathrm{Na}$ tabela 2, são apresentados os valores das coordenadas planas ( $\mathrm{Cx}$ e $\mathrm{Cy}$ ) determinadas para o polígono teste (PGT) e calculadas com GPS, nos quatro tempos de ocupação dos pontos, evidenciando as 
Tabela 1 - Distâncias (D), em metros, determinadas no PGT e as obtidas com receptores GPS nos tempos de ocupação de $30,15,10$ e 5 minutos e a diferença $(\Delta)$ entre elas.

\begin{tabular}{|c|c|c|c|c|c|c|c|c|c|}
\hline \multirow[b]{2}{*}{ V } & \multirow{2}{*}{$\begin{array}{c}\text { D } \\
\text { PGT }\end{array}$} & \multirow{2}{*}{$\begin{array}{c}\text { D } \\
\text { GPS }_{30}\end{array}$} & \multicolumn{3}{|c|}{ D } & \multirow{2}{*}{$\begin{array}{c}\text { D } \\
\text { GPS }_{10}\end{array}$} & \multicolumn{3}{|c|}{ D } \\
\hline & & & $\Delta_{30}$ & GPS $_{15}$ & $\Delta_{15}$ & & $\Delta_{10}$ & GPS $_{5}$, & $\Delta_{5}$ \\
\hline $\mathrm{P} 1$ & 202,001 & 201,979 & 0,022 & 202,032 & $-0,031$ & 202,030 & $-0,029$ & 202,070 & $-0,069$ \\
\hline $\mathrm{P} 2$ & 342,548 & 342,558 & $-0,010$ & 342,557 & $-0,009$ & 342,858 & $-0,310$ & 343,031 & $-0,483$ \\
\hline P3 & 349,153 & 349,136 & 0,017 & 349,139 & 0,014 & 349,016 & 0,137 & 349,141 & 0,012 \\
\hline P4 & 338,860 & 338,899 & $-0,039$ & 338,862 & $-0,002$ & 339,164 & $-0,304$ & 338,713 & 0,147 \\
\hline P5 & 421,546 & 421,501 & 0,045 & 421,538 & 0,008 & 421,676 & $-0,130$ & 421,528 & 0,018 \\
\hline$\Sigma$ & 1654,108 & 1654,073 & 0,035 & 1654,128 & $-0,020$ & 1654,744 & $-0,636$ & 1654,483 & $-\mathbf{0 , 3 7 5}$ \\
\hline
\end{tabular}

com GPS, observa-se que as diferenças entre as coordenadas planas (Cx e Cy) também foram centimétricas para $100 \%$ dos pontos. Pode-se verificar que as diferenças tiveram um certo aumento em relação aos tempos de 30 e 15 minutos. Quan-

diferenças entre elas. Analisando a tabela 2, verificase que, para o tempo de ocupação de 30 minutos, todas as coordenadas planas (Cx e Cy) do PGT e as obtidas com GPS apresentam diferenças centimétricas. Nas coordenadas $\mathrm{Cx}$ e $\mathrm{Cy}$, evidenciam-se que as diferenças foram maiores no ponto P5. Para o tempo de $15 \mathrm{minu}-$ tos, observa-se que todas as coordenadas apresentaram diferenças centimétricas. Porém, verifica-se que as diferenças em $\mathrm{Cx}$ foram maiores e para Cy menores, quando comparadas com as diferenças apresentadas no tempo de ocupação de 30 minutos. Pode-se verificar que as maiores diferenças em Cx e Cy ocorreram nos pontos $\mathrm{P} 4$ e $\mathrm{P} 5$, respectivamente. As coordenadas planas (Cx e Cy), determinadas para o tempo de 10 minutos, apresentaram diferenças centimétricas em todas as situações. Maiores diferenças em Cx e Cy foram evidenciadas nos pontos P5 e P3, respectivamente. Para o tempo de 5 minutos de ocupação dos pontos

Tabela 2 - Diferenças $(\Delta)$ entre as coordenadas planas (Cx e Cy) do polígono teste (PGT) e as obtidas com receptores GPS, em metros, nos tempos de ocupação de $30,15,10$ e 5 minutos.

\begin{tabular}{llllllc}
\hline P & Cx & & & \\
PGT & Cx & & & \\
GPS & & $\mathbf{C y}_{\text {PGT }}$ & $\mathbf{C y}_{\text {GPS }}$ & $\Delta \mathbf{C y}$ \\
\hline 30 minutos & & & & & & \\
P1 & 0,000 & 0,000 & $\mathbf{0 , 0 0 0}$ & 0,000 & 0,000 & $\mathbf{0 , 0 0 0}$ \\
P2 & $-201,838$ & $-201,815$ & $\mathbf{0 , 0 2 3}$ & 8,120 & 8,135 & $\mathbf{- 0 , 0 1 5}$ \\
P3 & $-427,402$ & $-427,406$ & $\mathbf{- 0 , 0 0 4}$ & $-249,678$ & $-249,655$ & $\mathbf{0 , 0 2 3}$ \\
P4 & $-334,275$ & $-334,290$ & $\mathbf{- 0 , 0 1 5}$ & $-586,182$ & $-586,145$ & $\mathbf{0 , 0 3 7}$ \\
P5 & $-39,115$ & $-39,089$ & $\mathbf{0 , 0 2 6}$ & $-419,727$ & $-419,686$ & $\mathbf{0 , 0 4 1}$ \\
15 minutos & & & & & & \\
P1 & 0,000 & 0,000 & $\mathbf{0 , 0 0 0}$ & 0,000 & 0,000 & $\mathbf{0 , 0 0 0}$ \\
P2 & $-201,838$ & $-201,871$ & $\mathbf{0 , 0 3 3}$ & 8,120 & 8,115 & $\mathbf{0 , 0 0 5}$ \\
P3 & $-427,402$ & $-427,465$ & $\mathbf{- 0 , 0 6 3}$ & $-249,678$ & $-249,670$ & $\mathbf{0 , 0 0 8}$ \\
P4 & $-334,275$ & $-334,349$ & $\mathbf{- 0 , 0 7 4}$ & $-586,182$ & $-586,162$ & $\mathbf{0 , 0 2 0}$ \\
P5 & $-39,115$ & $-39,187$ & $\mathbf{- 0 , 0 7 2}$ & $-419,727$ & $-419,707$ & $\mathbf{0 , 0 2 0}$ \\
10 minutos & & & & & & \\
P1 & 0,000 & 0,000 & $\mathbf{0 , 0 0 0}$ & 0,000 & 0,000 & $\mathbf{0 , 0 0 0}$ \\
P2 & $-201,838$ & $-201,869$ & $\mathbf{- 0 , 0 3 1}$ & 8,120 & 8,115 & $\mathbf{0 , 0 0 5}$ \\
P3 & $-427,402$ & $-427,700$ & $\mathbf{- 0 , 2 9 8}$ & $-249,678$ & $-249,864$ & $\mathbf{- 0 , 1 8 6}$ \\
P4 & $-334,275$ & $-334,343$ & $\mathbf{- 0 , 0 6 8}$ & $-586,182$ & $-586,163$ & $\mathbf{0 , 0 1 9}$ \\
P5 & $-39,115$ & $-38,729$ & $\mathbf{0 , 3 8 6}$ & $-419,727$ & $-419,896$ & $\mathbf{- 0 , 1 6 9}$ \\
5 minutos & & & & & & \\
P1 & 0,000 & 0,000 & $\mathbf{0 , 0 0 0}$ & 0,000 & 0,000 & $\mathbf{0 , 0 0 0}$ \\
P2 & $-201,838$ & $-201,897$ & $\mathbf{- 0 , 0 5 9}$ & 8,120 & 8,331 & $\mathbf{- 0 , 2 1 1}$ \\
P3 & $-427,402$ & $-427,872$ & $\mathbf{- 0 , 4 7 0}$ & $-249,678$ & $-249,751$ & $\mathbf{- 0 , 0 7 3}$ \\
P4 & $-334,275$ & $-334,203$ & $\mathbf{0 , 0 7 2}$ & $-586,182$ & $-586,093$ & $\mathbf{0 , 0 8 9}$ \\
P5 & $-39,115$ & $-39,176$ & $\mathbf{- 0 , 0 6 1}$ & $-419,727$ & $-419,703$ & $\mathbf{0 , 0 2 4}$ \\
\hline & & & & & &
\end{tabular}

do comparadas com o tempo de 10 minutos, observase que as coordenadas $\mathrm{Cx}$ do ponto P5 e Cy dos pontos $\mathrm{P} 3$ e $\mathrm{P} 5$ foram menores no tempo de 5 minutos de ocupação. Observa-se também que, em Cx a maior diferença foi no ponto P3 e em Cy no ponto P2.

\section{Área do polígono}

A área da poligonal determinada a partir dos dados obtidos com receptores GPS em cada tempo de ocupação pode ser vista na tabela 3 , bem como as diferenças em área quando comparada com a área da poligonal teste $\left(169157,4961 \mathrm{~m}^{2}\right)$, expressa em metros quadrados e em percentagem. Conforme pode ser observado na Tabela 3 , as diferenças de área variam entre 0,2641 e $222,5032 \mathrm{~m}^{2}$, o que corresponde a $0,0002 \%$ e $0,13155 \%$. O limite de tolerância em área utilizado por MARQUES (1991) é expresso por $\mathrm{T}=0,03 \mathrm{~A}^{1 / 2}+0,0006$ $\mathrm{A}$, na qual $\mathrm{T}$ é o limite de erro na área e $\mathrm{A}$ é a área considerada. Para o presente estudo, o limite de tolerância de erro em área é de $114 \mathrm{~m}^{2}$, aproximadamente. Analisando os valores apresentados na Tabela 3 , pode-se observar que esse limite é ultrapassado nos tempos de ocupação de 10 e 5 minutos. O tempo de ocupação de 15 minutos foi o que apresentou menor diferença na comparação das áreas obtidas pelos dois procedimentos.

\section{CONCLUSÃO}

Nas condições em que foi realizado esse trabalho e com base nos resultados obtidos, pode-se concluir que a reconstituição de uma poligonal topográfica depende da qualidade dos dados coletados pelos receptores GPS influenciados pelo tempo de ocupação dos pontos. Embora a Literatura recomende um tempo de ocupação de 30 minutos nos pontos, para linhas de base curtas $(<20 \mathrm{~km})$, com receptores

Ciência Rural, v. 33, n. 2, mar-abr, 2003. 
Tabela 3 - Área do polígono obtida com receptores GPS nos tempos de ocupação de 30,15, 10 e 5 minutos.

\begin{tabular}{lccc}
\hline $\mathrm{T}$ & Área $\left(\mathrm{m}^{2}\right)$ & $\Delta\left(\mathrm{m}^{2}\right)$ & $\Delta \mathbf{( \% )}$ \\
\hline 30 & 169164,7091 & 7,2130 & 0,0043 \\
15 & 169157,7605 & 0,2644 & 0,0002 \\
10 & 169379,9993 & 222,5032 & 0,1315 \\
5 & 169299,5262 & 142,0301 & 0,0840 \\
\hline
\end{tabular}

de uma freqüência, este estudo demonstra que o tempo de 15 minutos é adequado para obtenção de uma diferença centimétrica nos elementos analisados da poligonal. O emprego dessa metodologia mostrou ser viável, uma vez que permitiu a reconstitução de uma poligonal topográfica a partir dos dados obtidos com os receptores GPS. Entretanto, sugere-se que novos estudos sejam realizados para um melhor conhecimento e compreensão desta nova tecnologia, para que traga benefícios e vantagens à sociedade.

\section{REFERÊNCIAS BIBLIOGRÁFICAS}

HOFMANN-WELLENHOF, B.; LICHTENEGGER H.; COLLINS J. Global positioning system: theory and pratice. New York : Springer-Verlag Wien, 1997. 389p.

LAZZAROTTO, D.R. GPS - Sistema de posicionamento global. Disponível em: $<$ http://www.fatorgis.com.br.htm $>$ Acesso em: 28 jun, 2000

MAIA, T.C.B. Estudo e análise de poligonais segundo a NBR 13.133 e o sistema de posicionamento global. 1999. 176f. Dissertação (Mestrado em Transporte) - Escola de Engenharia de São Carlos, Universidade de São Pau10 .

MARQUES, G.G.M. Comparação da precisão entre os métodos de caminhamento perimétrico e irradiação, usados em levantamentos topográficos planimétricos. MIRA - Revista de Agrimensura e Cartografia, Criciúma, n. 08, p.20-21, 1991.

SOKKIA. Operator's Manual: GSS1A, GPS Survey Receiver. Lenexa, USA, 1999a. 5-5. "não-paginado".

SOKKIA. Spectrum Survey : reference manual. Lenexa, USA, 1999b. 7-1 "não-paginado".

TOPCON AMERICAN CORPORATION. TOPCON GPS Receivers- GP-R1, GP-R1D, GP-R1DP - Version 7 A: Operating Manual. New Jersey, USA, 1993. 219p. 